\title{
LXXXI. On the natural causes which operate in the formation of valleys
}

\author{
John Carr Esq.
}

To cite this article: John Carr Esq. (1809) LXXXI. On the natural causes which operate in the formation of valleys, Philosophical Magazine Series 1, 33:134, 452-459, DOI: $10.1080 / 14786440908562904$

To link to this article: http://dx.doi.org/10.1080/14786440908562904

曲 Published online: 18 May 2009.

Submit your article to this journal $\sqsubset \pi$

Џ Article views: 2

Q View related articles $\sqsubset$ 


\section{[ 452$]$}

IXXXI. On the Notural. Causes which operate in the Formation of Valleys. By John CarR, Esq.

"Revolving the circumstances of excavated vallevs in my mind, as I have observed them wonderfully distributed over the whole surface of large districts, effecting a descending outlet or drainage to any part : I have been lost in conjecturing any application of mechanical or kuown principles, that could have directed the almost irresistible forces, which effected this important, and as it were finishing operation on the matter of our globe, but refer the same to Omnipotent Power itself, acting, perhaps, in this instance, without the intervention of the agents whose operations in Nature the light of science enables us in so many instances to trace:"

Mr. John FAREY, Philosophical Magazine for April 1809.

To Mr. Tilloch,-Sir,

The above "most lame and impotent conclusion" furnishes a very singular instance of the great difference between observing and judging; between the accurate perception of effects, and the more rare and discriminating faculty of drawing from their common agreement and general combination, just and rational deductions of their cause. Phænomena so extensive, combined in such union, and operating so indispensable an office in the wise ceronomy of Nature, surely ought to have suggested a more natural and philosophical inference. To me, there are few things more evident than that "the irresistible forces" which have effected the excavation of valleys, are no other than the identical streams which now flow through them; and that by means so natural and obvious, as to excite extreme wonder how so experienced and intelligent an observer, as $\mathrm{Mr}$. Farey unquestionably is, can have surveyed the practical facts, and reflected on the subject, without arriving at the clearest conviction.

Every river which disembogues itself into the ocean is the great drainage trunk of a considerable extent of country, receiving through every part of its course lateral streams, which again receive others, and these others still, in so much that the river itself is frequently the receptacle of hundreds of other streams of various magnitude and extent; and not only the river, but every brook, however remotely connected, has its peculiar range of valleys, which afford it the 
most easy and direct communication with the stream into which it falls: and all these ranges of valleys are as subservient to, and as intimately connected with, the extensive and general system of draina e oi the country, as the streams themselves; and the uniform direction, general connection, and admirable subserviency of the whole, are so palpable, that we are irresistibly led to one of two conclusions, - - ither that the several ranges of valleys have been purposely and specially formed tor the streams which now flow through them, or that the streams themselves have scooped out their own peculiar vallevs. The former opinion is too absurd to merit a moment's attention ; and the latter has so many direct and positive proofs in its favour, as to yield the most satisfactory conviction to any impartial and competent mind, that will take an actual survey of the spring heads and courses of even the most trivial brooks.

But though there are no natural operations whatever, that from personal inspection more clearly illustrate themselves than this operation of streams in forming their own valleys, it is a subject of considerable difficulty when limited to mere description. The proof circumstances, in all their combinations, are distinct objects of visual inspection, and when spread out beneath the eye exhibit a connected chain of illustrative evidence irresistibly convincing; but the same impressive picture is comparatively faint, and its beautiful unity broken into fragments, like the landscape in the rippling stream, when held up to the "mind's eye" in the closet. Nevertheless there is a bold prominency in the outline of this natural scenery, which even the pen can trace, and I will endeavour to delineate it in a brief and hasty sketch.

The horizontal parallelism of the upper brows of valleys, and of the strata and their identity in the opposite banks, have long ago demonstrated that the strata were formerly continued across, and that the valleys have been formed by the strata being cut through and the missing portions carried away. The truth of this no one will question, who, by actual inspection, has given due attention to the facts upon which it rests.

The source of every stream is always situated on a higher Ff 3 
level than that of the country through which the valleys have been cut; and were they all filled up, there would still be a sufficient fall in the couutry for the streams to flow the same way : and as water, when left to itself, by its fluidity and gravitation constantly seeks the lowest place, we may always be assured that the conrse which the stream has taken is the lowest descent of the country in that direction. With these circumstances in view, let us sclect any individual stream, and suppose all its valleys to be filled up by replacing the very materials of the strata formerly carried off, thereby restoring the country to its pristine state before the valleys were excavated; and then, by attending to the course of the stream from its source, we shall acquire a clear and correct conception of the manner in which the valleys were originally formed. The old channel being in the lowest fall of the country, the stream will still flow in the same direction, but it will be on and over the newly restored materials, which we have supposed to be replaced; and it will first pass over that portion which has filled up the first valley, until it arrives at what was the lower end, which being now a declivity, it will be precipitated into the hollow below. In that hollow or flat the water will spread itself out into a lake, wider or narrower in its dimensions according to the form and bearing of the ground; and the lake continuing to fill, the water will rise over the level of the materials which filled up the second valley, and running on to where was the lower end, it will again descend the declivity into the hollow below, and will accumulate and spread itself until it again rises over the third valley, and descend again at the lower end; and in this manner it will continue its course, falling down every declivity which it reaches, and accumulating into a lake wherever the nature of the ground obstructs it, until the water reaches over the level of the obstructing rise; and the stream in this stage of its course will consist of a chain of streams, waterfalls and lakes, from its source to the channel of the next stream, or of the sea itself, the grand receptacle of the whole._L-Let us now attend to what will take place at the several falls. There, in every instance where the stratum is not an indurated rock, 
the momentum and action of the descending water will cut a channel, deep and expeditious in proportion to the height of the fall and the yielding nature of the stratum: and as this channel deepens, the unsupported sides will fall in, and the materials be swept away into the lake below. The water will continue this process, but with diminished force, as the inclined plane becomes less steep, until it has again excavated a valley similar to that which we have supposed to be filled up: and this new valley opening directly into the lake above, the lake will, in time, be completely drained off, and the stream will soon work itself out a limited channel in the alluvial materials which have formed the bottom of the lake, and which had been brought down from the detritus of the valley above. After a certain time the whole course of the stream will be changed, in this way, from a succession of streamis, waterfalis and lakes, into a succession of valleys and alluvial fints, such as we aclually now find existurg in the course of almost every stream. If the flat ground a hitle way bevond any valley be examined, below the vegetable mould, it will be found to consist of sand, gravel, and other alluvial materials precisely similar to the strata in the valley above; and if the valley immediately below be filled up, a lake will forthwith be formed above it, and covering the alluvial materials which had formed the bottom of the former lake:-and these two important facts, capable of the most direct proof in every district where valleys abound, are surely decisive evidence that the original course of the stream did consist of a chain of waterfalls and lakes, and that the falls have worn out the valleys backwards into the lakes above, thereby giving vent to their waters, and leaving the course of the streams, as we now find them, a succession of valleys and alluvial flats.

It may be easily imagined that the valley will be deep and capacious in proportion to the height of the waterfall where the excavation commences, and that the exit of the water in the lake above will increase the fall in the nest valley upwards; and it may also be readily conceived, that when the action of the water bas worn the inclined plune, down which it descends, to a certain point, all further excavation of the 
channel will cease, and that the stream may continue to flow for innumerable ages with but trivial alterations in its course. This is the true reason why we do not now see streams forming valleys, the work having been long since accomplished by the channels being reduced to their lowest descending level : and only by the bursting out of a new sprung head, in a situation distant from any other stream, could we now practically observe the progression of falls and lakes into valleys and flats, in the manner described. The progress of the stream flowing from such a new spring head would most assuredly establish the truth of every thing I have already statel. For it cannot be doubted that every stream must originally have formed its own channel; and it must be equally obvious, that when first left to find its own way over a great inequality of surface, it must frequently have precipitated down declivities into hollows, out of which it could have no other exit than by swelling into a lake, until the water rose over the level of the lowest ground which bounded the hollow.

In many cases a valley commences immediately at the source of a stream, just opening there and gradually deepening downwards to the lower end, where, questionless, the stream once fell, and where the cutting of the valley commenced; and this furm, of being shallow at the upper and deepening down to the lower end, where the fall of the stream first began to act for its formation, is also common to numerous valleys, more especially those near the spring heads; and while it perfectly accords with the action of the stream, it is utterly irreconcileable with any other explanation. Nothing, too, is more usual than the intersection of one valley with another at the confluence of two streams ; and in every such instance the angle of intersection of the valleys and streams is acute above and obtuse below, and the two streams invariably meet on precisely the same level. All this would naturally and necessarily result from the streams forming their own valleys and channels, but it is utterly impracticable to assign the most remote probable cause for the same union and unison of effects by any other natural means. 
In some cases, indeed, the capacious magnitude of the valley, compared with the diminutive size of the stream, might arrest our belief of so trivial an agent having accomplished so great a work; but those occasional and powerful floods to which every brook is subject, the immense duration of the action, and the yielding nature of the earthy materials removed, are amply sufficient to suppress every doubt and to reconcilè every difficulty.

There are multitudes of other practical facts which the actual survey of the course of streans readily supplies, and all of them speaking the same forcible language, of the streams thernselves being the only agents that have broken down the opposing obstacles in their course and reduced their channels to the regular gradation slopes down which we now find them flowing.

Those who may be desirous of verifying these observations on the formation of valleys, have only to visit the springheads of their neighbouring streams, tracing the channel downwards, and they will find little difficulty in marking the site of every former lake and waterfall, by only supposing the valley which lies before them to be filled up; and the obvious effect will be a lake at the upper and a waterfall at the lower end : and a proper examination of the soil below every valley will discover the very materials formerly brought down when the valley was excavating.

The very intimate connection between waterfalls and lakes, and their disappearance together, by the former effecting breaches into the latter, has been very fully dwelt upon; and accordingly where waterfalls now abound, there ought to be a corresponding abundance of lakes; and this is strikingly corroborated by the fact. Canada is productive of the most numerous and celebrated waterfalls, and there also, alove these falls, are the most numcrous and most extensive lakes on our globe.

Every waterfall that now exists is produced by a stratum of rock crossing the course of the stream, and it is solely owing to the indurated durability of the rock, that we now find a fall where we should otherwise have found a valley. This is so evident, that many of our most celebrated water- 
falls are not precipitated from an open height of higher ground, but down into a deep chasm, or rocky valley, formed, undeniably, by the violent action of the water, which bas continued, and is still continuing, from the detritus of the rock, to remove the fall higher up the stream : such strictly is the case with the far-famed Falls of Niagara. The surrounding country is nearly on the same level, and the river is propelled over an immense bed of rock, down into a profound valley, which extends for nine miles below the falls, and with every appearance of having been formed by the progressive removal of the fall backwards, in consequence of the gradual waste of the rock by the destructive action of the water.

But there is another point of view in which this magnificent waterfall ought to be considered as eminently illustrative of the subject under consideration. The height of the fall, and what are called the rapids immediately above it, is upwards of two hundred feet; and there is a still further considerable fall in the descent of the river from the lake above.

Now it certainly requires but a small effort of mind to perceive tbat the vast stratum of imperishable rock which crosses the channel of the river, has alone prevented the St. Lawrence from excavating one of the largest and most capacious valleys on our globe, and that the excavation would have extended upwards into lake Ontario, liberating its waters, and leaving the river to form, for itself, a channel through the central and deepest parts of the exhausted lake.

The retreat of these waters would be productive of another vast fall in the channel from lake Erie, and that fall again excavating a valley upwards, and into the lake, would occasion the exit of its waters; which again would produce a fall and excavation up into lake Huron, the retreat of whose waters would be followed by falls from, and excavations into, lakes Superior and Michigan; and hence this extensive chain of immense lakes would disappear, leaving in its place an equally extensive chain of valleys and alluvial flats, similar, but on a far more gigantic scale, to the thousands 
of lakes which have disappeared by the same natural process in every country.

I fear, Mr. Erlitor, I have trespassed much too far on the limits of your truly estimable record of scientific papers; yet I trust the subject is one of superior interest, by bringing us acquainted with the origin of those beautiful excavations which adurn so much of our landscape, and add so much of pleasurable variety to every excursion. They offer, however, still higher claims to our attention from their paramount usefu!ness in the provident ceconomy of Nature, by operating, with such admirable and subservient address, and such a harmonized system of combination, as the universal conduits of all the waters of every country.

I am, sir, your most obedient humble servant,

Princes Street, Manchester,

John Carr.

June 10, 1809 .

LXXXII. Introduction to the Study of Mineralogy. By $M$. HAUX.

[Concluded from p. 401.]

$B_{\text {ut the authors of systems of mineralogy, without even }}$ excepting chemists, have followed a very different course. They have considered each metal as the base of a particular genus; and in the case in which this metal existed per se, in the state of native metal, it would form the first species of the genus; and its combinations with different principles would give the other species. Thus, in the genus of copper, we should have successively, as species, native copper, oxide of copper, sulphuret of copper, carbonate of copper, muriate of copper, \&cc. In short, metallic substances have characters so striking, that they have been adopted with one accord, as the fixed points around which all the combinations ought to rally of which they form part.

Now, uniformity of method would require, that the same rule which had been followed in the arrangement of metallic substances should also preside over tbat of substances produced by the union of an earth with an acid; i. e. lime, for example, 